\title{
Gambaran Kepercayaan Guru Dalam Literasi Anak Usia Dini
}

\author{
Gian Fitria Anggraini' ${ }^{1}$, Susanthi Pradini, Vivi Irzalinda \\ ${ }^{1}$ FKIP Universitas Lampung, Jl. Prof. Dr. Soemantri Brojonegoro No.1 \\ email: gian21@fkip.unila.ac.id
}

\begin{abstract}
Teachers' Beliefs in Early Childhood Literacy. This study aimed to describe and analyze the teacher beliefs of early childhood teachers. The research method was used descriptive quantitative. Sampling was done by random sampling as many as 85 teachers. The data analyze by using descriptive analysis to find the mean, standard deviation, and categorization. The results showed that most of the teachers still belonged to traditional literacy beliefs. Teachers need to be encouraged to build constructivist knowledge and skills so that the implementation of literacy learning in early childhood is more optimal.
\end{abstract}

Keywords: teacher literacy, literacy belief, early childhood

\begin{abstract}
Abstrak. Gambaran Kepercayan Guru Dalam Literasi Anak Usia Dini. Penelitian ini bertujuan untuk menggambarkan dan menganalisis kepercayaan literasi (teacher belief) guru anak usia dini. Metode penelitian menggunakan deskriptif kuantitatif. Pengambilan sampel dilakukan secara random sampling sebanyak 85 orang guru. Adapun analisis data menggunakan analisis deskriptif untuk mencari nilai mean, standar deviasi, serta kategorisasi. Hasil penelitian menunjukkan bahwa sebagian besar guru masih tergolong pada kepercayaan literasi yang tradisional. Guru perlu didorong untuk membangun pengetahuan serta keterampilan konstruktivisnya agar pelaksanaan pembelajaran literasi pada anak usia dini lebih optimal.
\end{abstract}

Kata Kunci: literasi guru, kepercayaan literasi, anak usia dini 


\section{PENDAHULUAN}

Keterampilan literasi merupakan dasar dari kemampuan mengambil keputusan, pemberdayaan diri, serta keaktifan dalam berpartisipasi secara lokal maupun global (Stromquist, 2006). Tidak hanya itu kemampuan literasi juga merupakan indikator kesuksesan seseorang untuk menghadapi tantangan dalam setiap jenjang pendidikan. Literasi merupakan kebutuhan universal, dimana manusia membutuhkannya untuk memenuhi kebutuhan dasar, sekaligus mengembangkan nilai-nilai sosial, budaya, ekonomi dan politik di komunitasnya.

Sukses atau tidaknya kemampuan literasi tergantung pada stimulasi yang didapatkan oleh seseorang. Stimulasi ini tentunya didapatkan dari lingkungan. Lingkungan yang dapat membangkitkan semangat berliterasi tentunya akan lebih kaya budaya literatnya. Lingkungan sosial pada hakekatnya dapat kita bagi menjadi lingkungan yang paling kecil hingga lingkungan yang paling luas. Konsep pendidikan paling kecil dimulai dari keluarga dan juga sekolah (Bronfenbrenner, 1979). Sekolah menjadi salah satu sentral pengembangan budaya literat. Kunci pengembangan budaya literat ini tentunya dipegang oleh guru sebagai pemegang utama pembelajaran di dalam kelas. Namun, setiap praktisi pendidikan memiliki perspektif yang berbeda akan praktek dan proses pembelajaran literasi. Dimana perbedaan pandangan tersebut akan menghasilkan kualitas serta bentuk praktek literasi itu sendiri.

Guru sebagai kunci dalam mendidik di sekolah juga memiliki kepercayaan yang berbeda terhadap proses pembelajaran literasi. Perbedaan kepercayaan itulah yang sering kali menyamarkan kebutuhan akan literasi anak usia dini yang sesungguhnya. Muatan pembelajaran literasi di sekolah saat ini masih banyak menekankan pada hapalan atau sekedar latihan menulis dan membaca saja, tanpa dimaknai secara utuh. Padahal berdasarkan pandangan emergent, literasi tidak lagi dipandang sebagai keterampilan yang terpisah dan memposisikan anak sebagai pembelajar pasif yang memerlukan latihan terstruktur secara terus menerus (Pugh \& Rohl, 2000). Mengambil konsep emergent dan sosiokultural, literasi pada anak dibentuk melalui pengalaman sebelumnya serta interaksinya dengan lingkungan, salah satunya melalui interaksi antara guru dan anak. Penelitian yang dilakukan oleh peneliti sebelumnya juga mengungkapkan bahwa interaksi yang dilakukan oleh guru secara langsung dapat meningkatkan kemampuan berbicara anak (Anggraini \& Sofia, 2016). Kualitas interaksi literasi yang terjadi antara guru dan anak akan sangat dipengaruhi oleh kepercayaan yang dimiliki guru terhadap pembelajaran (Mayo, 2010).

Kepercayaan yang dimiliki oleh guru dalam mengajarkan literasi tentu saja sangat krusial dalam membantu anak mencapai potensi literatnya. Salah satu penelitian mengungkapkan bahwa kepercayaan yang dimiliki guru terhadap pembelajaran literasi dapat mempengaruhi praktek serta perkembangan literasi anak (Al-Maadadi \& Ihmeideh, 2016). Penelitian lain juga mengungkapkan bahwa lingkungan sekolah memiliki peran yang cukup aktif dengan capaian kemampuan membaca anak usia dini (Friedlander, 2013).

Penelitian ini bertujuan untuk menggambarkan bagaimana kepercayaan guru terhadap literasi dan prakteknya, sehingga temuan penelitian ini dapat menggambarkan pola pengajaran yang dilakukan guru dalam dunia literasi.

\section{METODE}

Penelitian ini dilakukan dengan menggunakan deskriptif kuantitatif untuk menggambarkan persepsi guru terhadap literasi anak usia dini serta gambaran karakteristik guru PAUD terhadap konsep belief dan practice terutama dalam pembelajaran literasi. Pemilihan lokasi penelitian dilakukan dengan cluster random 
sampling dari TK Negeri dan Swasta di Bandar Lampung. Adapun pengambilan responden dilakukan secara acak (simple random sampling). Jumlah responden adalah 85 guru yang semuanya adalah perempuan dan memiliki latar belakang pendidikan yang berbeda-beda.

Pengumpulan data dilakukan dengan mengumpulkan data primer yang meliputi karakterstik guru, serta orientasi guru dalam pembelajaran literasi. Pengambilan data dilakukan dengan menggunakan questionare yang dikembangkan dari Literacy Orientation Survey (LOS) yang memiliki 2 dimensi yaitu belief dan practice (Lenski, Wham, \& Griffey, n.d.,2014) dengan modifikasi. Reliabilitas variabel persepsi guru dalam pembelajaran literasi adalah $0.776(\alpha)$. Kuesioner persepsi guru dalam pembelajaran literasi terdiri dari 28 item. 14 item untuk dimensi belief dan 14 item dimensi practice. Setiap item diberi nilai dengan skala 1 sampai 5, dengan ketentuan sebagai berikut: sangat tidak setuju (1), tidak setuju (2), ragu-ragu (3), setuju (4), dan sangat setuju (5). Dari 14 item pada dimensi belief terdapat 6 item negative, dan dari 14 item pada dimensi practice ada 1 item negatif. Masing-masing item negatif diberi skala dengan ketentuan: sangat tidak setuju (5), tidak setuju (4), ragu-ragu (3), setuju (2) dan sangat setuju (1). Skor pada masing-masing dimensi dijumlahkan dan diperoleh skor total. Skor total yang diperoleh diformasikan ke dalam kategori yang diadaptasi dari kategori LOS kuesioner. Kategori tersebut diantaranya adalah sebagai berikut: a. skor 80-105 (traditional); b. skor 106-124 (eclectic); c. skor 125-140 (constructivist). Skor total pada dimensi belief dikategorikan berdasarkan pengkategorian pada LOS kuesioner sebagai berikut: a. skor 40-51 (traditional); b. 52-61(eclectic); c. 62-70 (construktivist). Sedangkan skor total pada dimensi practice dikategorikan berdasarkan pengkategorian LOS sebagai berikut: a. skor 34-46 (traditional); b. skor 47-59 (eclectic); c. skor 60-70 (constructivist). Analisis data untuk data primer, yaitu karakteristik guru dilakukan melalui analisis deskriptif, yaitu mean, standar deviasi, nilai min-max, dan nilai presentase.

\section{HASIL DAN PEMBAHASAN Karakteristik Guru}

Berdasarkan hasil analisis data karakteristik guru, diketahui sebaran responden berdasarkan jenis kelamin semua adalah guru perempuan (100\%), untuk kategori usia, sebaran responden 52.9\% berusia antara 30-50 tahun. Selain itu, sebaran responden menunjukkan $50.6 \%$ memiliki pengalaman mengajar rata-rata hingga 12 tahun. Hampir sebagian responden juga memiliki latar belakang pendidikan S1.

Tabel 1. Sebaran Responden Berdasarkan Karakteristik

\begin{tabular}{|c|c|c|c|c|c|}
\hline No & Variabel & $\mathbf{n}$ & $\%$ & $\begin{array}{c}\text { Rata- } \\
\text { Rata } \pm \\
\text { Std }\end{array}$ & $\begin{array}{l}\text { Min- } \\
\text { Max }\end{array}$ \\
\hline \multirow[t]{2}{*}{1.} & $\begin{array}{l}\text { Jenis } \\
\text { Kelamin } \\
\end{array}$ & & & & \\
\hline & Perempuan & 85 & 100 & - & - \\
\hline \multirow[t]{5}{*}{2.} & $\begin{array}{l}\text { Usia } \\
\text { Guru }\end{array}$ & & & $\begin{array}{c}38.9 \\
\pm 11.41\end{array}$ & $\begin{array}{l}14- \\
59\end{array}$ \\
\hline & 12-18 tahun & 1 & 1.2 & & \\
\hline & 18-30 tahun & 21 & 24.7 & & \\
\hline & $30-50$ tahun & 45 & 52.9 & & \\
\hline & $>50$ tahun & 18 & 21.2 & & \\
\hline \multirow[t]{4}{*}{3.} & $\begin{array}{l}\text { Lama } \\
\text { Mengajar }\end{array}$ & & & $\begin{array}{l}14.76 \pm 1 \\
1.41\end{array}$ & $0-37$ \\
\hline & $0-12$ tahun & 43 & 50.6 & & \\
\hline & 13-24 tahun & 18 & 21.2 & & \\
\hline & 25-37 tahun & 24 & 28.2 & & \\
\hline \multirow[t]{4}{*}{4.} & $\begin{array}{l}\text { Latar } \\
\text { Belakang } \\
\text { Pendidikan } \\
\end{array}$ & & & $\begin{array}{l}2.66 \pm 0 . \\
75\end{array}$ & $1-3$ \\
\hline & SMA/SMK & 14 & 16.5 & & \\
\hline & D3 & 1 & 1.2 & & \\
\hline & S1 & 70 & 82.4 & & \\
\hline
\end{tabular}

\section{Orientasi Literasi Guru}

Berdasarkan hasil kategori orientasi literasi guru (tabel 2), sebagian besar responden termasuk pada kategori traditional (62.4\%). Sebagian kecil masuk pada kategori eclectic (35.35), dan hanya sedikit yang masuk pada kategori 
constructivist $(2.4 \%)$.

Tabel 2. Sebaran Responden berdasarkan Kategori Orientasi Literasi Guru

\begin{tabular}{llcc}
\hline No & \multicolumn{1}{c}{ Kategori } & n & \% \\
\hline 1. & Traditional(80- 105) & 53 & 62.4 \\
2. & Eclectic (106-124) & 30 & 35.3 \\
3. & Constructivist(125-140) & 2 & 2.4 \\
\hline \multirow{2}{*}{} & Total & 85 & 100.0 \\
& Rata-rata \pm Std & $103.02 \pm 11.11$ \\
& Min - Max & $72-136$ \\
\hline
\end{tabular}

Kemudian, untuk melihat lebih rinci orientasi literasi guru dari sisi kepercayaan (belief) dan praktek (practice), hasil sebaran responden menunjukkan bahwa baik kepercayaan (belief) maupun praktek, sebagian besar guru termasuk dalam kategori eclectic (49.41\% dan 63.5\%) (tabel $3)$.

Kategori orientasi literasi juga dipetakan berdasarkan perbandingan besarnya nilai kepercayaan (belief) serta praktek responden (tabel 4). Data menunjukkan bahwa responden yang memiliki skor kepercayaan (belief) lebih besar daripada praktek cenderung traditional (38.8\%). Sedangkan responden yang nilai kepercayaan (belief) lebih kecil dibandingkan practice cenderung eclectic (24.7\%), begitu juga dengan responden yang nilai kepercayaan (belief) sama dengan nilai practice, memiliki kecenderungan eclectic (2.4\%). Dari data juga dapat disimpulkan bahwa sebagian besar responden memiliki nilai kepercayaan (belief) yang lebih besar dibandingkan nilai prakteknya yang kesemuanya condong pada kategori traditional (62.4\%).

Tabel 3. Sebaran Responden berdasarkan Kategori Belief dan Practice (Teachers' Belief and Practice)

\begin{tabular}{|c|c|c|c|c|}
\hline \multirow[t]{2}{*}{ No } & & \multirow[t]{2}{*}{ Kategori } & & \\
\hline & & & $\mathbf{n}$ & $\%$ \\
\hline \multirow[t]{2}{*}{1.} & Belief & $\begin{array}{l}\text { Traditional } \\
(40-51)\end{array}$ & 41 & 48.24 \\
\hline & & $\begin{array}{l}\text { Eclectic } \\
(52-61)\end{array}$ & 42 & 49.41 \\
\hline
\end{tabular}

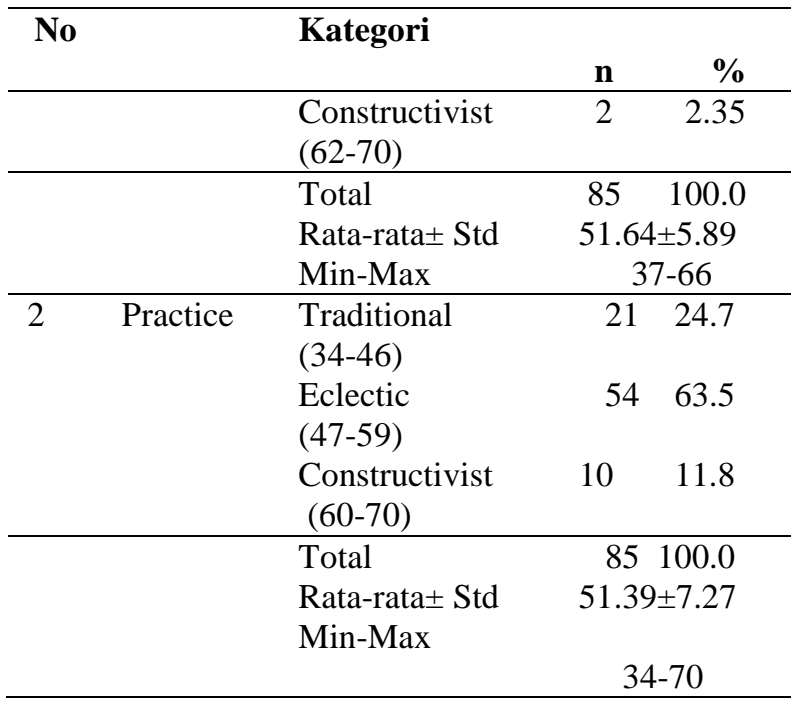

Tabel 4. Sebaran Kategori Berdasarkan Nilai Belief dan Practice

\begin{tabular}{cccccc}
\hline Kategori & & $\begin{array}{c}\text { Tradi- } \\
\text { tional }\end{array}$ & Eclectic & $\begin{array}{c}\text { Construc- } \\
\text { tivist }\end{array}$ & Total \\
\hline $\begin{array}{c}\text { Belief } \\
>\text { Practice }\end{array}$ & $\mathbf{n}$ & 33 & 7 & 0 & 40 \\
\cline { 2 - 6 } & $\mathbf{\%}$ & 38.8 & 8.2 & 0 & \\
\hline Belief $<$ & $\mathbf{n}$ & 19 & 21 & 2 & 42 \\
Practice & $\mathbf{\%}$ & 22.4 & 24.7 & 2.4 & \\
\cline { 2 - 6 } $\begin{array}{c}\text { Belief }= \\
\text { Practice }\end{array}$ & $\mathbf{n}$ & 1 & 2 & 0 & 3 \\
\hline \multirow{2}{*}{ Total } & $\mathbf{\%}$ & 1.2 & 2.4 & 0 & \\
\cline { 2 - 6 } & $\mathbf{\%}$ & 62.4 & 35.3 & 2.4 & 100 \\
\hline
\end{tabular}

Dari segi lama mengajar, rata-rata responden yang mengajar dibawah 13 tahun memiliki nilai practice yang cenderung traditional (15) dan eclectic (20) begitu pun dengan nilai kepercayaan (belief), cenderung traditional (19) dan eclectic (24). Adapun pada responden yang memiliki pengalaman mengajar di bawah 25 tahun memiliki nilai practice dan belief yang cenderung eclectic (15 dan 11). Namun, yang menarik adalah responden yang memiliki lama mengajar di atas 25 tahun memiliki nilai practice yang cenderung eclectic (19), namun nilai belief yang tradisional (13). (tabel 5). 
Tabel 5. Sebaran Responden Berdasarkan

Tabel 6. Sebaran responden berdasarkan

Lama Mengajar dengan Belief dan Practice

\begin{tabular}{|c|c|c|c|c|c|}
\hline \multirow[t]{6}{*}{ No } & Kategori & \multicolumn{3}{|c|}{ Practice } & \multirow[t]{2}{*}{ Total } \\
\hline & & $\begin{array}{c}\text { Traditi } \\
\text { onal }\end{array}$ & Eclectic & $\begin{array}{l}\text { Constructi } \\
\text { vist }\end{array}$ & \\
\hline & $\begin{array}{l}\text { Lama } \\
\text { Mengajar } \\
(0-12 \\
\text { tahun })\end{array}$ & 15 & 20 & 8 & 43 \\
\hline & $\begin{array}{l}\text { (13-24 } \\
\text { tahun) }\end{array}$ & 3 & 15 & 0 & 18 \\
\hline & $\begin{array}{l}\text { (25-37 } \\
\text { tahun) }\end{array}$ & 3 & 19 & 2 & 24 \\
\hline & Total & 21 & 54 & 10 & 85 \\
\hline \multirow[t]{2}{*}{ No } & Kategori & \multicolumn{3}{|c|}{ Belief } & Total \\
\hline & & $\begin{array}{c}\text { Traditi } \\
\text { onal }\end{array}$ & Eclectic & $\begin{array}{c}\text { Construc } \\
\text { tivist }\end{array}$ & \\
\hline 1 & $\begin{array}{l}\text { Lama } \\
\text { Mengajar } \\
(0-12 \\
\text { tahun })\end{array}$ & 19 & 24 & 0 & 43 \\
\hline 2 & $\begin{array}{l}(13-24 \\
\text { tahun) }\end{array}$ & 7 & 11 & 0 & 18 \\
\hline 3 & $\begin{array}{l}(25-37 \\
\text { tahun) }\end{array}$ & 13 & 9 & 2 & 24 \\
\hline & Total & 39 & 44 & 2 & 85 \\
\hline
\end{tabular}
usia dengan Belief dan Practice

\begin{tabular}{|c|c|c|c|c|c|}
\hline \multirow[t]{2}{*}{ No } & \multirow[b]{2}{*}{ Kategori } & \multicolumn{3}{|c|}{ Practice } & \multirow[t]{2}{*}{ Total } \\
\hline & & $\begin{array}{c}\text { Traditi } \\
\text { onal }\end{array}$ & Eclectic & $\begin{array}{c}\text { Constr } \\
\text { uctivis } \\
t\end{array}$ & \\
\hline \multirow[t]{7}{*}{1} & $\begin{array}{l}\text { Usia } \\
(12-18 \\
\text { tahun) }\end{array}$ & 0 & 1 & 0 & 1 \\
\hline & $\begin{array}{l}(18-30 \\
\text { tahun) }\end{array}$ & 8 & 8 & 5 & 21 \\
\hline & $\begin{array}{l}(31-50 \\
\text { tahun) }\end{array}$ & 11 & 30 & 4 & 45 \\
\hline & $\begin{array}{l}(>50 \\
\text { tahun) }\end{array}$ & 2 & 15 & 1 & 18 \\
\hline & Total & 21 & 54 & 10 & 85 \\
\hline & \multirow[b]{2}{*}{ Kategori } & \multicolumn{3}{|c|}{ Belief } & Total \\
\hline & & $\begin{array}{c}\text { Traditi } \\
\text { onal }\end{array}$ & Eclectic & $\begin{array}{c}\text { Constr } \\
\text { uctivis } \\
t\end{array}$ & \\
\hline \multirow[t]{5}{*}{2} & $\begin{array}{l}\text { Usia } \\
(12-18 \\
\text { tahun) }\end{array}$ & 0 & 1 & 0 & 1 \\
\hline & $\begin{array}{l}(18-30 \\
\text { tahun })\end{array}$ & 11 & 10 & 0 & 21 \\
\hline & $\begin{array}{l}(31-50 \\
\text { tahun) }\end{array}$ & 18 & 26 & 1 & 45 \\
\hline & $\begin{array}{l}(>50 \\
\text { tahun) }\end{array}$ & 10 & 7 & 1 & 18 \\
\hline & Total & 39 & 44 & 2 & 85 \\
\hline
\end{tabular}

responden juga dikategorikan berdasarkan usia. Responden dengan rentang usia remaja awal (12-18 tahun) memiliki nilai practice dan belief yang cenderung eclectic (1). Responden dengan rentang remaja akhir (18-30 tahun), memiliki nilai practice yang cenderung traditional dan eclectic, serta memiliki nilai belief yang cenderung eclectic (11). Adapun responden yang memiliki rentang usia dewasa awal/akhir (31-50 tahun), memiliki nilai practice yang cenderung eclectic (30), begitupun dengan nilai belief yang cenderung eclectic (26). Sedangkan untuk responden dengan kateori usia berada pada rentang usia lansia (50 tahun ke atas), memiliki nilai practice yang cenderung eclectic (15) dan belief yang cenderung tradisional (10). (tabel 6).

\section{Pembahasan}

Berdasarkan hasil penelitian ditemukan bahwa orientasi literasi guru secara umum cenderung traditional. Meskipun demikian nilai kepercayaan (belief) dan juga praktek guru dalam literasi cenderung eclectic. Orientasi literasi yang tradisional menandakan bahwa guru tersebut masih menggunakan metode membaca trasdisional seperti basal reading instruction, contohnya mengeja, dll. Selain itu, guru juga masih menggunakan instruksi langsung sebagai instruksi utama pembelajarannya. Guru yang tradisional pun pada dasarnya masih memandang siswa atau anak didik sebagai bejana kosong yang harus diisi (Lenski, Wham, \& Griffey, 1998).

Namun demikian, berdasarkan pemetaan orientasi terhadap praktek dan 
kepercayaan (belief) literasi guru cenderung eclectic. Orientasi eclectic menunjukkan bahwa praktek serta pandangan guru dalam mengajar merupakan kolaborasi antara metode membaca yang tradisional dan konstruktivits. Pemilihan literatur pun masih bersifat basal atau literatur-literatur yang mengutamakan latihan membaca.

Berdasarkan hasil penelitian juga ditemukan bahwa sebagian besar guru memiliki nilai kepercayaan (belief) yang lebih besar dibandingkan dengan nilai prakteknya. Hal ini menunjukkan bahwa kebanyakan guru belum merasa yakin untuk menggunakan nilai atau keyakinan konstruktivis di dalam kelas (Lenski et al., 1998). Keyakinan konstruktivis berkaitan dengan kemampuan guru dalam memahami dunia anak, dimana guru mendorong anak didik untuk mengkonstruk pengetahuan dan pemahamannya secara mandiri (Brooks \& Brooks, 1999). Konsep konstruktivis memandang anak sebagai pembelajar yang aktif. Anak sebagai pusat dalam proses pembelajaran (student centered) yang aktif menggali serta memahami berbagai informasi maupun fenomena kognitif dan sosial yang ada di lingkungannya (Kalpana, 2014). Namun pada kenyataanya masih banyak ditemukan praktek pembelajaran yang lebih berpusat pada guru (teacher centered) bahkan di sekolah-sekolah yang kurikulumnya sudah menggunakan pendekatan child-centered (Õun, SaarUgaste, \& Niglas, 2008). Berdasarkan hasil penelitian di Indonesia juga masih banyak guru yang menggunakan teknik konvensional dalam pembelajarannya, dalam artian proses belajar-mengajar masih didominasi oleh pemberian materi dari guru atau teacher centered learning (Antika, 2014). Penelitian terdahulu juga menyebutkan bahwa dalam kegiatan literasi guru masih memposisikan anak sebagai pelajar yang pasif dan terpusat pada guru (Anggraini \& Irzalinda, 2019). Kondisi ini salah satunya dipengaruhi oleh kesiapan guru dalam menghadapi tantangan pengajaran terutama dalam mengubah mindset dari pembelajaran yang berpusat pada guru atau materi (subject or teacher centered approach) kepada pembelajaran yang berpusat pada anak (child centered approach) (Maynard \& Chicken, 2010).

Pemahaman konstruktivis seorang guru tentunya akan dipengaruhi oleh apa yang mereka yakini tentang pembelajaran serta pengalaman (Lenski et al., 1998). Berkaitan dengan hasil pemetaan yang menggambarkan kecenderungan guru memiliki nilai kepercayaan (belief) yang lebih tinggi ketimbang praktek, memperkuat teori bahwa nilai kepercayaan yang dipegang oleh seorang guru memiliki peran dan kontribusinya dalam aktualisasi kerja atau cara pengajaran maupun pembelajaran yang guru lakukan di dalam kelas (Biesta \& Tedder, 2007). Seperti dua mata panah yang mengarah pada satu objek yang sama, maka antara kepercayaan dan praktek akan saling berkaitan satu sama lain. Meskipun demikian, ternyata kualitas pengajaran seorang guru tidak hanya ditentukan oleh nilai kepercayaan saja, tapi juga dapat dipengaruhi oleh faktor-faktor lain seperti pengembangan diri (sef development) serta pertimbangan (consideration) yang didapatkan guru dari pengalaman mengajar (Biesta, Priestley, \& Robinson, 2015). Hal inilah yang memungkinkan seorang guru memiliki kualitas praktek pengajaran yang lebih tinggi meskipun belum seimbang dengan nilai-nilai pembelajaran yang dipercayainya.

Sejalan dengan pendapat yang menyatakan bahwa guru yang memiliki nilai praktek lebih besar daripada kepercayaannya menandakan bahwa guru tersebut memerlukan beberapa penguatan atau pemahaman yang lebih mendalam tentang kenapa dan bagaimana seorang guru memilih strategi pembelajaran tertentu (Lenski et al., 1998).

Pada pembelajaran literasi, pemahaman terdahulu mengenai cara pembelajaran literasi yang tradisional sudah melekat lama sehingga meskipun telah mendapat pengetahuan baru mengenai cara 
yang konstruktivis masih berada di ranah kognitif. Sehingga kecenderungan guru memiliki kepercayaan (belief) yang eclectic. Untuk mencapai kepercayaan (belief) dan praktik yang konstruktivis diperlukan input pengetahuan dan praktik yang dapat lebih meyakinkan para guru pada cara konstruktivis terutama dengan pengalaman mengajar yang lebih lama (diatas 25 tahun) yang memiliki kepercayaan (belief) yang lebih kuat terhadap cara tradisional. Sehingga nilai praktik guru daoat bergerak dari cara yang eclectic ke konstruktivis.

\section{SIMPULAN}

Berdasarkan hasil dan pembahasan, didapatkan simpulan bahwa, secara umum para guru PAUD di Bandar Lampung memiliki kepercayaan (belief) dan praktik yang eclectic dalam pembelajaran literasi di kelas. Sebagian guru masih memiliki kepercayaan (belief) yang tradisional dalam mengajarkan pembelajaran literasi pada anak usia dini, terutama pada guru yang memiliki pengalaman mengajar diatas 25 tahun. Hal ini menjadi dapat dipahami karena pembelajaran literasi yang konstruktivis merupakan pengetahuan yang baru bagi para guru sehingga belum dapat diyakini sebagai pendekatan yang dapat berhasil dalam pembelajaran literasi. Namun, secara praktik para guru telah menerapkan pembelajaran literasi yang eclectic yang merupakan percampuran antara pembelajaran literasi yang tradisional dan konstruktivis. Hal tersebut bermakna bahwa Selain kepercayaan (belief) guru terhadap pendekatan pembelajaran literasi tertentu, dalam hal ini tradisional terdapat pula pengetahuan baru akan penekatan pembelajaran literasi konstruktivis yang berperan pada praktik guru dalam pembelajaran literasi yang eclectic.

\section{REFERENSI}

Al-Maadadi, F., \& Ihmeideh, F. (2016). Early writing development: kindergarten teachers' beliefs about emergent writing in Qatari preschool settings. International Journal of Early Years Education, 24(4), 435-447. https://doi.org/10.1080/09669760.2016 .1244047

Anggraini, F. G., \& Sofia, A. (2016). Rekonstruksi Kecakapan Sosial Guru Dalam Pengembangan Berbicara Anak Usia Dini. Jurnal Ilmiah Visi, 11(2), 11-120.

https://doi.org/https://doi.org/10.21009 /JIV.1102

Antika, R. R. (2014). Proses Pembelajaran Berbasis Student Centered Learning. BioKultur, III(1), 251-263.

Biesta, G., Priestley, M., \& Robinson, S. (2015). The role of beliefs in teacher agency. Teachers and Teaching: Theory and Practice, 21(6), 624-640. https://doi.org/10.1080/13540602.2015 .1044325

Biesta, G., \& Tedder, M. (2007). Agency and learning in the lifecourse: Towards an ecological perspective. Studies in the Education of Adults, 39(2), 132149. https://doi.org/10.1080/02660830.2007 .11661545

Bronfenbrenner. (1979). The Ecology of Human Development. Cambridge: Harvard University Press.

Brooks, J. G., \& Brooks, M. G. (1999). The Case For Contructivist Classrooms. Association for Supervision and Curriculum Development. Virginia USA: Association for Supervision and Curriculum Development. https://doi.org/10.1017/CBO97811074 15324.004

Friedlander, E. (2013). Environmental factors associated with early reading achievement in the developing world: A cross-national study. International Journal of Educational Research, 57, 25-38. https://doi.org/10.1016/j.ijer.2012.10.0 06

Kalpana, T. (2014). A Constructivist Perspective on Teaching and Learning: 
A Conceptual Framework. International Research Journal of Social Sciences, 3(1), 27-29. Retrieved from http://www.isca.in/IJSS/Archive/v3/i1/ 6.ISCA-IRJSS-2013-186.pdf

Lenski, S. D., Wham, M. A., \& Griffey, C. (n.d.). Reading Research and Literacy orientation survey: A survey to clarify teachers, beliefs and practices, (October 2014), 37-41. https://doi.org/10.1080/193880798095 58266

Lenski, S. D., Wham, M. A., \& Griffey, D. C. (1998). Literacy orientation survey: A survey to clarify teachers' beliefs and practices. Reading Research and Instruction, 37(3), 217-236. https://doi.org/10.1080/193880798095 58266

Maynard, T., \& Chicken, S. (2010). Through a different lens: Exploring Reggio Emilia in a Welsh context. Early Years, 30(1), 29-39. https://doi.org/10.1080/095751409034 43000

Mayo, J. (2010). A Study of Early Childhood Education Teachers Beliefs and Practices About Early Literacy Learning. Marshall University.

Õun, T., Saar-Ugaste, A., \& Niglas, K. (2008). The views of kindergarten staff on educational objectives in postsocialist society. Early Child Development and Care, 178(1), 81-98. https://doi.org/10.1080/030044306007 89316

Pugh, B. C., \& Rohl, M. (2000). Literacy Learning In The Early Years. New South Wales: Allen \& Unwin.

Stromquist, N. P. (2006). The Political Benefits of Adult Literacy. Education for All Global Monitoring Report 2006 Literacy for Life. (Vol. 2). https://doi.org/10.1080/193131508020 10285 